\title{
Structure dependent antioxidant capacity of phlorotannins from Icelandic Fucus vesiculosus by UHPLC-DAD-ECD-QTOFMS
}

Hermund, Ditte Baun; Plaza, Merichel; Turner, Charlotta; Jonsdottir, Rosa; Kristinsson, Hordur G.; Jacobsen, Charlotte; Nielsen, Kristian Fog

\section{Published in:}

Food Chemistry

Link to article, DOI:

10.1016/j.foodchem.2017.08.032

Publication date:

2018

Document Version

Peer reviewed version

Link back to DTU Orbit

Citation (APA):

Hermund, D. B., Plaza, M., Turner, C., Jonsdottir, R., Kristinsson, H. G., Jacobsen, C., \& Nielsen, K. F. (2018). Structure dependent antioxidant capacity of phlorotannins from Icelandic Fucus vesiculosus by UHPLC-DADECD-QTOFMS. Food Chemistry, 240, 904-909. https://doi.org/10.1016/j.foodchem.2017.08.032

\section{General rights}

Copyright and moral rights for the publications made accessible in the public portal are retained by the authors and/or other copyright owners and it is a condition of accessing publications that users recognise and abide by the legal requirements associated with these rights.

- Users may download and print one copy of any publication from the public portal for the purpose of private study or research.

- You may not further distribute the material or use it for any profit-making activity or commercial gain

- You may freely distribute the URL identifying the publication in the public portal 


\section{Accepted Manuscript}

Short communication

Structure dependent antioxidant capacity of phlorotannins from Icelandic Fucus vesiculosus by UHPLC-DAD-ECD-QTOFMS

Ditte B. Hermund, Merichel Plaza, Charlotta Turner, Rosa Jónsdóttir, Hordur

G. Kristinsson, Charlotte Jacobsen, Kristian Fog Nielsen

PII:

S0308-8146(17)31359-6

DOI: http://dx.doi.org/10.1016/j.foodchem.2017.08.032

Reference: FOCH 21581

To appear in:

Food Chemistry

Received Date: $\quad 1$ February 2017

Revised Date: $\quad 7$ August 2017

Accepted Date: $\quad 9$ August 2017

Please cite this article as: Hermund, D.B., Plaza, M., Turner, C., Jónsdóttir, R., Kristinsson, H.G., Jacobsen, C., Nielsen, K.F., Structure dependent antioxidant capacity of phlorotannins from Icelandic Fucus vesiculosus by UHPLC-DAD-ECD-QTOFMS, Food Chemistry (2017), doi: http://dx.doi.org/10.1016/j.foodchem.2017.08.032

This is a PDF file of an unedited manuscript that has been accepted for publication. As a service to our customers we are providing this early version of the manuscript. The manuscript will undergo copyediting, typesetting, and review of the resulting proof before it is published in its final form. Please note that during the production process errors may be discovered which could affect the content, and all legal disclaimers that apply to the journal pertain. 
Structure dependent antioxidant capacity of phlorotannins from Icelandic Fucus vesiculosus by UHPLC-DAD-ECD-QTOFMS

Ditte B. Hermund $^{1 *}$, Merichel Plaza ${ }^{2}$, Charlotta Turner ${ }^{2}$, Rosa Jónsdóttir ${ }^{3}$, Hordur G. Kristinsson ${ }^{3}$, Charlotte Jacobsen ${ }^{1}$, Kristian Fog Nielsen ${ }^{4}$

${ }^{1}$ Division of Food Technology, National Food Institute, Technical University of Denmark, DK2800 Kgs. Lyngby, Denmark

${ }^{2}$ Centre for Analysis and Synthesis, Department of Chemistry, Lund University, SE 22100 Lund, Sweden

${ }^{3}$ Matís ohf., Vínlandsleid 12, 113 Reykjavík, Iceland

${ }^{4}$ Division of Metabolic Signalling and Regulation, Department of Systems Biology, Technical

University of Denmark, DK-2800 Kgs. Lyngby, Denmark

*Corresponding author: dbala@food.dtu.dk, Ph. +45 35887000

\section{Key words}

Brown algae, screening, free radical scavenging, MS/MS 


\begin{abstract}
Brown algae are rich in polyphenolic compounds, phlorotannins, which have been found to possess high in vitro antioxidant capacity, especially DPPH radical scavenging activity, due to the high number of hydroxyl groups. Whereas, the overall antioxidant capacity of brown algae extracts has been widely studied, the antioxidant capacity of individual phlorotannins has been rarely explored. The aim of this study was to determine the structure dependant antioxidant capacity of phlorotannins from Icelandic brown algae, Fucus vesiculosus. The antioxidant capacity of individual phlorotannins was determined by an on-line method using liquid chromatography and an electrochemical detector followed by quadrupole Time of Flight mass spectrometry (UHPLC-DADECD-QTOFMS). Tentative structural elucidation of 13 phlorotannin isomers from EAF was obtained by LC-DAD-QTOFMS, ranging from 374 to $870 \mathrm{Da}$. On-line determination of antioxidant capacity of the individual phlorotannins generally showed that low molecular phlorotannins exhibited higher antioxidant capacity and that the capacity decreased with polymerisation.
\end{abstract}




\section{Introduction}

New research confirms the antioxidant potential of Icelandic brown algae Fucus vesiculosus extracts as natural antioxidants in fish muscle and foods enriched with fish oil, to limit oxidation of marine polyunsaturated fatty acids, like EPA and DHA (eicosapentaenoic and docosahexaenoic acid), in these types of products (Halldorsdottir, Sveinsdottir, Gudmundsdottir, Thorkelsson, \& Kristinsson, 2014; Hermund, Yesiltas, Honold, Jónsdóttir, Kristinsson, \& Jacobsen, 2015; Honold, Jacobsen, Jònsdòttir, Kristinsson, \& Hermund, 2016; Karadag et al, 2016; Hermund et al., 2016). Phlorotannins, the major polyphenolics in brown algae, have been found to possess high in vitro antioxidant activity (Koivikko, Loponen, Honkanen, \& Jormalainen, 2005; Wang, Jónsdóttir, \& Ólafsdóttir, 2009). These compounds are a subgroup of tannins, which are formed by the polymerization of phloroglucinol units (PGU) (1,3,5-trihydroxybenzene, $\mathrm{M}_{\mathrm{w}} 126 \mathrm{Da}$ ) (Ragan \& Glombitza, 1986). Low molecular weight (LMW) phlorotannins between 4 and 8 PGUs, have been found to be predominant in F. vesiculosus (Steevensz et al., 2012; Heffernan, Brunton, FitzGerald, \& Smyth, 2015; Kirke, Smyth, Rai, Kenny, \& Stengel, 2017). However, studies have also shown the presence of highly polymerised phlorotannins of up to 16 PGUs ( 2000 Da) (Heffernan et al., 2015; Kirke et al., 2017). According to Martínez and Castañeda (2013) phlorotannins can be divided into three major groups: 1) fucols, 2) phloroethols and 3) fucophloroethols. Fucols are phlorotannin polymers in which the PGUs are connected only by $\mathrm{C}-\mathrm{C}$ (phenyl linkage) bonds in meta position. Phloroethols consist of PGUs, which are linked only by C-O-C (aryl-ether) bonds. Linear phloroethols can have ortho-, meta- or para-oriented biphenyl ether bridges.

Fucophloroethols are a mixture of both bi-aryl and aryl-ether bonds allowing a variety of compounds in linear, branched and heterocyclic fashions. Due to the high complexity of phlorotannin structures only few studies have dealt with their characterization and identification. Phlorotannin levels in seaweed extracts are commonly expressed as total phenolic content (TPC) 
using assays like the Folin-Ciocalteu assay. This assay involves oxidation of phenolic rings by phosphotungstic and phosphomolybdic acids, resulting in formation of a blue complex which can be detected spectrophotometrically (725-765nm) (Singleton \& Rossi, 1965). However, FolinCiocalteu assay is not specific for phlorotannins and will also include other reducing substances present in the seaweed extracts. Hence, more in-depth studies of identification and characterization of phlorotannins are needed.

The availability of advanced chromatographic and mass spectrometric techniques gives the possibility for tentative identification of phlorotannins. Wang et al. (2012) and Heffernan et al. (2015) both characterized phlorotannins extracted from $F$. vesiculosus using such techniques. Heffernan et al. (2015) used Liquid Chromatography with tandem MS for profiling fractions of phlorotannins from brown algae. Wang et al. (2012) performed simple purification of $80 \%(\mathrm{v} / \mathrm{v})$ ethanol extract derived from $F$. vesiculosus by liquid-liquid partitioning, using ethyl acetate, to obtain fractions rich in phlorotannins. Hereafter, semi-preparative column chromatography were applied on the fractions before high performance liquid chromatography (HPLC) electrospray (ESI) coupled to MS and MS/MS analysis and tentative identification of phlorotannins was obtained. Colorimetric assays were then applied on the phlorotannin fractions to study antioxidant properties such as radical scavenging activity in order to gain information on how polymerization and molecular size influence the antioxidant capacity. Colorimetric assays such as 2,2-diphenyl-1picrylhydrazyl radical scavenging assay (DPPH), is typically used to determine the antioxidant capacity of antioxidants. However, on-line cyclic voltammetry approach can measure the ability of individual compounds to donate electrons and thus provides information of their antioxidant capacity. Plaza, Kariuki and Turner (2013) studied the antioxidant contribution of phenolic compounds from apples by coupling an electrochemical detector (ECD) to an HPLC. They found no significant difference $(p<0.05)$ between using this method for determining antioxidant capacity 
or the colorimetric antioxidant assays, indicating that the cyclic voltammetry results (oxidation potential) can be interpret in the same way as radical scavenging capacity from e.g. DPPH. With this method, it would be possible to determine the antioxidant capacity of individual phlorotannins, and thereby provide an in-depth knowledge of how phlorotannins contribute to the overall antioxidant capacity of seaweed extracts.

The aim of this study was to evaluate the structure dependant antioxidant capacity of phlorotannins by a fast screening method. This was performed on a purified phlorotannin-rich fraction from Icelandic brown algae $F$. vesiculosus, which previously has shown great potential as natural antioxidant in food emulsions (Hermund et al, 2015). The individual phlorotannins and their antioxidant capacity were identified and characterized by HPLC-DAD-ECD-QTOFMS analysis of EAF.

\section{Materials and Methods}

\subsection{Chemicals and Reagents}

All chemicals were of analytical grade. Formic acid and acetic acid were from Merck (Darmstadt, Germany). Phloroglucinol standard was purchased from Sigma-Aldrich (St. Louis, MI, USA). The ultrapure water used was obtained from a Milli-Q (Millipore, Billerica, MA, USA) instrument.

\subsection{Algae material, solvent extraction, partitioning and fractionation}

Solvent extraction and partitioning were performed by Matís in Iceland according to Wang et al.

(2012). The seaweed (Fucus vesiculosus L.) was collected from intertidal water in the Hvassahraun coastal area near Hafnarfjordur, southwestern Iceland, in September 2011. At the collecting site the seaweed was washed with clean seawater to remove salt crystals, epiphytes and sand attached to the surfaces of the samples and transported to the laboratory. The samples were carefully rinsed with 
tap water and wiped with paper towel. The samples were freeze-dried, pulverised into powder and stored at $-80^{\circ} \mathrm{C}$ prior to extraction.

An $80 \%(v / v)$ aqueous ethanol extract (EE) was obtained by dispersing five grams of freeze-dried algal powder in $100 \mathrm{~mL} \mathrm{80 \%} \mathrm{(v/v)} \mathrm{ethanol} \mathrm{and} \mathrm{incubated} \mathrm{in} \mathrm{the} \mathrm{platform} \mathrm{shaker} \mathrm{(InnovaTM} \mathrm{2300,}$ New Brun- swick Scientific, Edison, NJ) for $24 \mathrm{~h}$ at $200 \mathrm{rpm}$ and at room temperature. The mixture was centrifuged at $2168 \mathrm{~g}$ for $10 \mathrm{~min}$ at $4^{\circ} \mathrm{C}$ and filtered $(20-25 \mu \mathrm{m}$ particle retention) to obtain a liquid extract. EE was subjected to liquid-liquid partitioning to yield semi-pure phlorotannin-rich fractions on the basis of polarity. The solvent partitioning was performed by collecting $100 \mathrm{~mL} \mathrm{EE}$ and concentrating it to a small volume by $\mathrm{N}_{2}$ evaporation. The concentrate was partitioned with $n$ hexane, ethyl acetate, and $n$-butanol, successively, yielding four fractions including $n$-hexane-, ethyl acetate-, and $n$-butanol-soluble fractions and the aqueous residues. Solvent were evaporated from the fraction and the remains were freeze-dried. The ethyl acetate fraction (EAF) was used in this study because of the high TPC associated with this fraction. This is in agreement with Wang et al. (2012) who found ethyl acetate to be efficient in concentrating/enriching phlorotannins from crude F. vesiculosus extracts. EAF was stored at $-80^{\circ} \mathrm{C}$ until further required. Prior to analysis the powders was dissolved in demineralised water.

\subsection{HPLC-DAD-ECD analysis}

Instrumentation. The method setup was based on a similar method used for polyphenols and phenolic acids (Plaza et al., 2013; Safafar, Myerson Van Wagenen, Møller, \& Jacobsen 2015). It consisted of an UltiMate- $3000^{\circledR}$ HPLC system (Dionex, Thermo Fisher, Germering, Germany) with a photodiode array detector (DAD). The detection wavelengths used were: 200, 280, 350, 370, and $520 \mathrm{~nm}$. An ECD instrument (Bioanalytical System Inc., West Lafayette, IN, USA) was attached 
just after the DAD to do online amperometric detection. The setup has been described in Plaza et al. (2013).

Chromatographic separation. Separation was obtained on a Phenomenex Prodigy $3 \mu \mathrm{m}$ ODS 3 150x $2 \mathrm{~mm}$ column. The mobile phase consisted of ammonium formate buffer (A) (pH 3, $20 \mathrm{mM}$ formic acid), $60 \mathrm{mM}\left(\mathrm{NH}_{4} \mathrm{HCOO} / \mathrm{HCOOH}\right)$ in water; and acetonitrile (B) (20 mM formic acid). The mobile phases were purged with nitrogen to remove oxygen. The gradient elution analysis program was as follows: 0-2 $\mathrm{min}, 0 \%$ (B); 2-16 min, increasing to $40 \%$ (B); 16-18 min, increasing to $100 \%$ (B), with 17 min of post-time at a flow rate of $0.3 \mathrm{~mL} / \mathrm{min}$. All compounds had eluted within the first $17 \mathrm{~min}$ and therefore the chromatograms are of this duration. The column temperature was set at $25^{\circ} \mathrm{C}$, the injection volume was $2 \mu \mathrm{L}$, and the vial tray was held at $4{ }^{\circ} \mathrm{C}$. For instrument validation, phloroglucinol standard ( $1 \mathrm{mg} / \mathrm{mL}$ for HPLC) and the associated retention time were used as a control. All analyses were conducted in triplicates.

\subsection{UHPLC-DAD-QTOFMS analysis}

Instrumentation. Ultra-high performance liquid chromatography-DAD-quadrupole time of flight mass spectrometry (UHPLC-DAD-QTOFMS) was performed on an Agilent Infinity 1290 UHPLC system (Agilent Technologies, Santa Clara, CA, USA) equipped with a DAD coupled to an Agilent 6545 QTOF MS equipped with Agilent Dual Jet Stream electrospray ion source (Kildgaard et al., 2014). MS and MS/MS were performed at m/z 100-1600 and auto-MS/MS was done at 10, 20, and 40 eV. Hexakis (2,2,3,3-tetrafluoropropoxy)phosphazene (Apollo Scientific Ltd., Cheshire, UK) at 921.23 was used as lock mass in positive and negative mode as the $[\mathrm{M}+\mathrm{H}]^{+}$and $[\mathrm{M}+\mathrm{HCOO}]^{-}$ions respectively.

Chromatographic separation. Separation was obtained similar to the method used for HPLC-DADECD analysis with some alterations. The gradient elution analysis program was as follows: 0-2 min, 
$0 \%$ (B); 2-16 min, increasing to $40 \%$ (B); $16-18 \mathrm{~min}$, increasing to $100 \%$ (B), with $17 \mathrm{~min}$ of posttime at a flow rate of $0.3 \mathrm{~mL} / \mathrm{min}$. All compounds had eluted within the first $17 \mathrm{~min}$ and therefore the chromatograms are of this duration. The column temperature was set at $25^{\circ} \mathrm{C}$, the injection volume was $2 \mu \mathrm{L}$. For instrument validation, phloroglucinol standard $(0.1 \mathrm{mg} / \mathrm{mL}$ for $\mathrm{LC})$ and the associated retention time were used as a control.

\subsection{Data analysis}

The areas (nAs) of the ECD responses for the EAF were calculated (mean $\pm \mathrm{SD}$ ). UHPLC-DADQTOF data analysis was performed in MassHunter 6.00 where the base peak chromatograms (BPC) were made with major background ions subtracted. For finding known phlorotannins the Find-ByFormula function in Masshunter was used searching for the following singly charged adducts: ESI ${ }^{+}$, $[\mathrm{M}+\mathrm{H}]^{+}$and $[\mathrm{M}+\mathrm{Na}]^{+} ; \mathrm{ESI}^{-},[\mathrm{M}-\mathrm{H}]^{-},[\mathrm{M}+\mathrm{HCOO}]^{-}$.

\section{Results and discussion}

\subsection{Structural elucidation of phlorotannins}

The Extracted Ion Chromatograms (EIC) of deprotonated molecular ions ([M-H] $]^{-}$) from the most common phlorotannins found in literature (eckol $(\mathrm{m} / \mathrm{z} 371.0409)$, fucophloroethol $(\mathrm{m} / \mathrm{z} 373.0565)$, 7-phloroeckol ( $\mathrm{m} / \mathrm{z}$ 495.0569), fucodiphloroethol ( $\mathrm{m} / \mathrm{z}$ 497.0725), phlorofucofuroeckol $(\mathrm{m} / \mathrm{z}$ 601.0624), fucotriphloroethol $(\mathrm{m} / \mathrm{z}$ 621.0886), dieckol $(\mathrm{m} / \mathrm{z}$ 741.0733), and fucophloroethols with six $(\mathrm{m} / \mathrm{z} 745.1046)$, and seven phloroglucinol units (PGUs) $(\mathrm{m} / \mathrm{z} 869.1207))$, were used for the study of phlorotannins in EAF by UHPLC-DAD-QTOFMS. Furthermore the elemental compositions were verified by the accurate mass $( \pm 5 \mathrm{ppm})$ and isotopic patterns.

In Fig. 1. the Base Peak Chromatogram (BPC) of EAF is shown together with the UV chromatogram and EICs of the selected ions. In the EICs, some peaks were overlapping due to 
insource fragmentation (i.f.) giving false/positive results when consulting MS-data, e.g. one peak in EIC of $m / z 373$ was found to be an insource fragmentation of $m / z 497$. When taking this into account the EICs revealed well-defined and abundant ions of 11 (1-11) compounds tentatively corresponding to phlorotannins and corresponding with the UV chromatogram, and two compounds (12-13), which were only found in trace amounts and were not so well-defined, neither by UV. There were no responses in the UV chromatogram, which did not correspond to the studied ions. The MS study of the ions allowed the detection of several isomers. The isomers were studied in negative ionization mode to investigate the fragmentation patterns with the aim of getting closer to an exact structural identification of the isomers.

Compounds 6, 7 and 8, in negative mode, showed similar fragmentation patterns in which some ions are characteristic of phlorotannins fragmentation, e.g. for compounds with losses of one and two water molecules (-18.0101 (m/z 603.0778) and -36.0209 (m/z 585.0670), respectively), loss of 1 PGU and water (-126.0324, $-18.0101(\mathrm{~m} / \mathrm{z} 477.0454))$, and loss of 2 PGUs and water, as well as the presence of deprotonated molecular ion of phloroglucinol ( $\mathrm{m} / \mathrm{z} 125.0133)$. Thus, these three compounds are suggested to be phlorotannins composed of five PGUs, possibly isomers of fucotriphloroethol. In the supplementary material (Fig. S1), the structure of fucotriphloroethol (linear) and suggested fragmentation of this phlorotannin are shown. It is most likely that the loss of one and two water occurs first, followed by fragmentation from the ether-end due to the higher lability of this bond compared to the phenyl-linkage.

In Table 1 the fragmentation patterns in negative mode of the 13 identified phlorotannin compounds (including isomers) are listed. Isomers of phlorotannins trimers with $[\mathrm{M}-\mathrm{H}]^{-}$at $m / z 373$ (compound 1-3) were observed, which correspond tentatively to fucophloroethol. Isomers of phlorotannins tetramers with $[\mathrm{M}-\mathrm{H}]^{-}$at $\mathrm{m} / \mathrm{z} 497$ (compound 4-5) were observed, which correspond tentatively to fucodiphloroethol. Furthermore, isomers with $[\mathrm{M}-\mathrm{H}]^{-}$at $m / z, 745$ (compound 9-11) and $m / z, 869$ 
were tentatively identified as fucophloroethols with six or seven PGUs, respectively. Hydrogen migration was observed (noted as either +2 or -2 in Table 1 ) in some of the fragments. Even though the fragmentation patterns of the isomers showed some differences, indicating structural diversity, it was not possible to make further elucidation of the structures. Further structural identification of the isomers would require severe purification of the extracts as well as NMR (nuclear magnetic resonance). Heffernan et al. (2015) also using MS and no NMR, found that $F$. vesiculosus contained phlorotannins in the range of 3 to 16 PGU, with the most abundant phlorotannins at a low molecular weight range, e.g. $m / z 497$ (4PGU), $m / z, 745$ (6PGU) and $m / z, 869$ (7PGU).

\subsection{Structure dependent antioxidant capacity of phlorotannins}

Along with the identification of phlorotannins in EAF, on-line detection of the antioxidant capacity of individual phlorotannins was carried out by HPLC-DAD-ECD. It was possible to detect compound 2 to 11 by UV (Fig. 2). However, for some compounds it was not possible to distinguish the ECD response, e.g. compound 3 and 9 have different composition, but could not be separated in the ECD, hence the ECD response of these two compounds were not determined. Non-separable ECD responses of compounds with the same composition were though determined. Hence, determination of antioxidant capacity of individual phlorotannins was only carried out for compound 2 to 11, excluding compound 3 and 9, by calculating the ECD response (nAs). The results are shown in Table 1.

Shibata, Ishimaru, Kawaguchi, Yoshikawa and Hama (2008) and Audibert, Fauchon, Blanc, Hauchard, and Ar Galla (2010) studied the antioxidant activity of semi-purified extracts of phlorotannin fractions, of different molecular weight range, obtained from brown algae. They found that with increased molecular weight of the isolated phlorotannin fractions the antioxidant capacity(DPPH radical scavenging) decreased. 
The present study is the first of its kind to evaluate antioxidant capacity of individual phlorotannins and not just fractions with phlorotannins in a specific molecular weight range. Compound 2, an isomer of fucophloroethol (3 PGUs) showed the highest antioxidant capacity, and the capacity seemed to decrease with increased polymerization of phlorotannins (Table 1). However, there was one exception as Compound 6 consisting of 5 PGUs showed higher antioxidant capacity than phlorotannins consisting of 4 PGUs (Compound 4 and 5).

These results indicate that it is the availability of hydroxyl groups more than the polymerization, which determines the antioxidant capacity of the phlorotannins. It can be hypothesised that large phlorotannin polymers might fold in a way, which encloses the OH-groups inside the structure, and therefore poorer antioxidant capacity of large phlorotannins was observed. However, the enclosed structure and unavailable $\mathrm{OH}$-groups are dependent on the branching of the phlorotannins, therefore one isomer of phlorotannin consisting of 5 PGUs showed higher antioxidant capacity compared with other isomers, which might be branched in a different way that favours folding of the compound in a way which decreases their antioxidant capacity. As mentioned, this has to be verified with additional NMR analysis.

\section{Concluding Remarks}

Tentative structural elucidation of 13 phlorotannin isomers from EAF was obtained by UHPLCDAD-QTOFMS ranging from 374 to $870 \mathrm{Da}$. It was not possible to determine the structural differences between isomers, though the fragmentation patterns obtained showed clear differences presumably due to different branching of the phlorotannins. On-line determination of antioxidant capacity of the individual phlorotannin generally showed that low molecular weight phlorotannins exhibited higher antioxidant capacity and also that the capacity decreased with polymerisation. This 
method could be used as a fast screening of complex seaweed extracts to identify the presence of highly antioxidative phlorotannins, e.g. isomers of fucophloroethol (3 PGUs).

\section{Acknowledgments}

The study was part of the project "Novel bioactive seaweed based ingredients and products" financed by Nordic Innovation. The work was done as part of work package 2 "Characterization of ingredients". We are grateful to Agilent Technologies for the Thought Leader Donation of the UHPLC-DAD-QTOF system.

\section{Reference list}

Audibert, L., Fauchon, M., Blanc, N., Hauchard, D., \& Ar Galla, E. (2010). Phenolic compounds in the brown seaweed Ascophyllum nodosum: Distribution and radical-scavenging activities. Phytochemical Analysis, 21, 399-405.

Halldorsdottir, S. M., Sveinsdottir, H., Gudmundsdottir, A., Thorkelsson, G., \& Kristinsson, H. G. (2014). High quality fish protein hydrolysates prepared from by-product material with Fucus vesiculosus extract. Journal of Functional Foods, 9, 10-17.

Heffernan, N., Brunton, N.P., FitzGerald, R.J., \& Smyth, T.J. (2015). Profiling of the molecular weight and structural isomer abundance of macroalgae-derived phlorotannins, Marine Drugs, 13, $509-528$.

Hermund, D. B., Yesiltas, B., Honold, P., Jónsdóttir, R., Kristinsson, H. G., \& Jacobsen, C. (2015). Characterisation and antioxidant evaluation of Icelandic $F$. vesiculosus extracts in vitro and in fishoil-enriched milk and mayonnaise. Journal of Functional Foods, 19, 828-841.

Hermund, D.B., Karadag, A., Andersen, U., Jónsdóttir, R., Kristinsson, H.G., Alasalvar, C., \& Jacobsen, C. (2016). Oxidative Stability of Granola Bars Enriched with Multilayered Fish Oil 
Emulsion in the Presence of Novel Brown Seaweed Based Antioxidants. Journal of Agricultural and Food Chemistry, 64, 8359-8368.

Honold, P.J, Jacobsen, C., Jònsdòttir, R., Kristinsson, H.G., \& Hermund, D.B. (2016). Potential seaweed-based food ingredients to inhibit lipid oxidation in fish-oil-enriched mayonnaise.

European Food Research and Technology, 242, 571-584.

Karadag, A., Hermund, D. B., Jensen, L. H. S., Andersen, U., Jónsdóttir, R., Kristinsson, H. G., Alasalvar, C., \& Jacobsen, C. (2016). Oxidative stability and microstructure of 5\% fish-oil-enriched granola bars added natural antioxidants derived from brown alga Fucus vesiculosus. European Journal of Lipid Science and Technology, 118. doi: 10.1002/ejlt.201500578.

Kildgaard, S., Mansson, M., Dosen, I., Klitgaard, A., Frisvad, J.C., Larsen, T.O., \& Nielsen, K.F. (2014). Accurate Dereplication of Bioactive Secondary Metabolites from Marine-Derived Fungi by UHPLC-DAD-QTOFMS and a MS/HRMS Library. Marine Drugs., 12, 3681-3705.

Kirke, D. A., Smyth, T. J., Rai, D. K., Kenny, O., \& Stengel, D.B. (2017). The chemical and antioxidant stability of isolated low molecular weight phlorotannins. Food Chemistry, 221, 11041112.

Koivikko, R., Loponen, J., Honkanen, T., \& Jormalainen, V. (2005). Contents of soluble, cell-wallbound and exuded phlorotannins in the brown alga Fucus vesiculosus, with implications on their ecological functions. Journal of Chemical Ecology, 31, 195-212.

Martínez, J.H.I., \& Castañeda, H.G.T. (2013). Preparation and Chromatographic Analysis of Phlorotannins. Journal of Chromatographic Science, 51, 825-838. 
Plaza, M., Kariuki, J., \& Turner, C. (2013). Quantification of Individual Phenolic Compounds' Contribution to Antioxidant Capacity in Apple: A Novel Analytical Tool Based on Liquid Chromatography with Diode Array, Electrochemical, and Charged Aerosol Detection. Journal of Agricultural and Food Chemistry, 62, 409-418.

Ragan, M.A., \& Glombitza, K.W. (1986). Phlorotannins, brown algal polyphenols. In F.E. Round, \& D.J. Chapman (Eds.), Progress in Phycological Research (pp. 129-241). Bristol: Biopress.

Safafar, H., Myerson Van Wagenen, J., Møller, P., \& Jacobsen, C. (2015). Carotenoids, phenolic compounds and tocopherols contribute to the antioxidative properties of some microalgae species grown on industrial wastewater. Marine Drugs, 13(12), 7339-7356.

Shibata, T., Ishimaru, K., Kawaguchi, S., Yoshikawa, H., \& Hama, Y. (2008). Antioxidant activities of phlorotannins isolated from Japanese Laminariaceae. Journal of Applied Phycology, 20, $705-711$.

Singleton, V.L, \& Rossi, J.L. (1965). Colorimetry of total phenolics with phosphomolybdicpphosphotungstic acid reagents. Amererican Journal of Enology and Viticulture, 16, 144-158.

Wang, T., Jónsdóttir, R., \& Ólafsdóttir, G. (2009). Total phenolic compounds, radical scavenging and metal chelating of extracts from Icelandic seaweed. Food Chemistry, 116, 240-248.

Wang, T., Jónsdóttir, R., Liu, H., Gu, L., Kristinsson, H. G., Raghavan, S., \& Ólafsdóttir, G. (2012). Antioxidant capacities of phlorotannins extracted from the brown algae Fucus vesiculosus. Journal of Agricultural and Food Chemistry, 60, 5874-5883. 


\section{Highlights}

- Tentative structural elucidation of 13 phlorotannin isomers from Fucus vesiculosus

- On-line determination of antioxidant capacity of 9 individual phlorotannins

- Generally the antioxidant capacity decreased with polymerization

- Structure dependant antioxidant capacity was found 


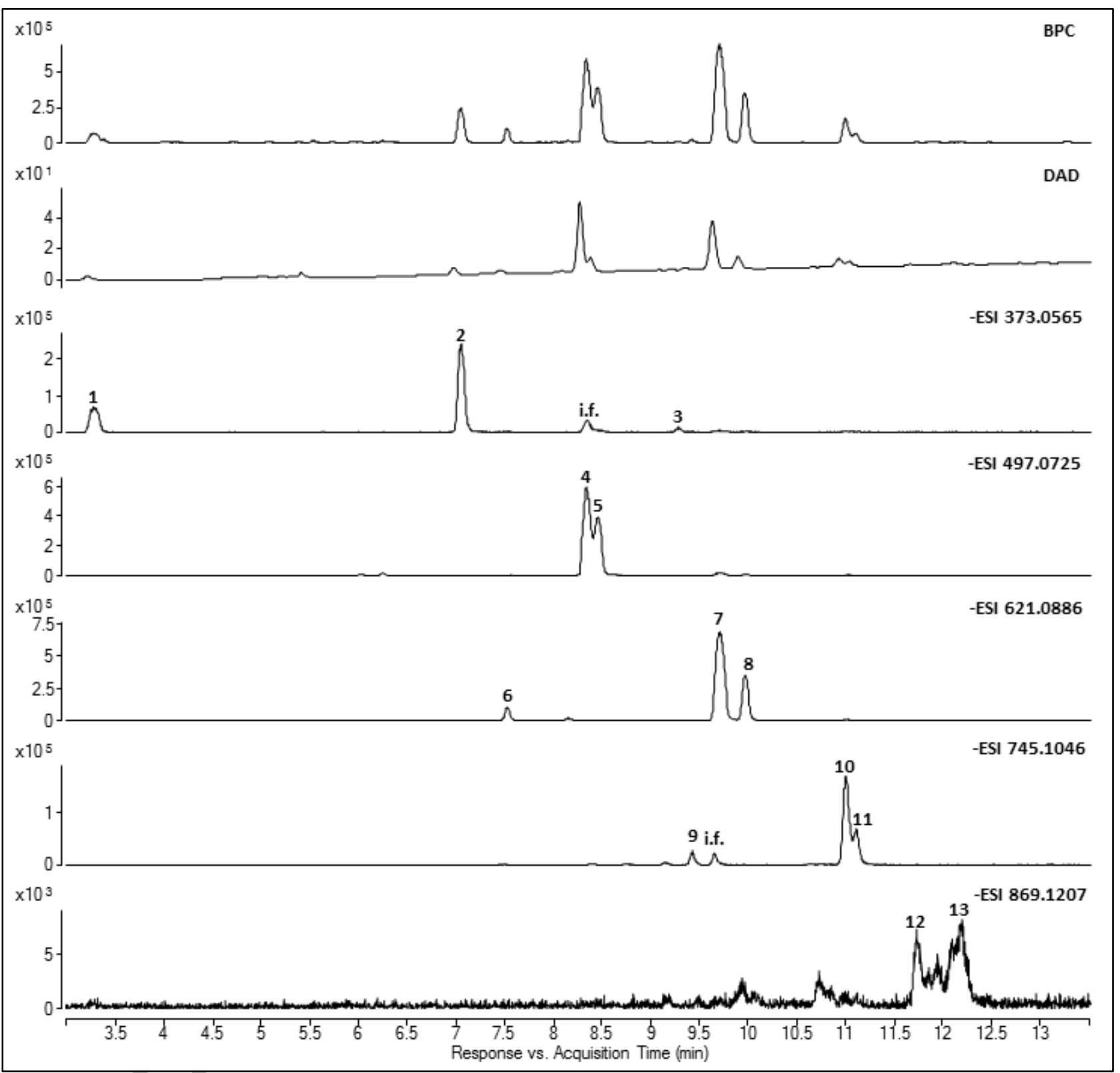




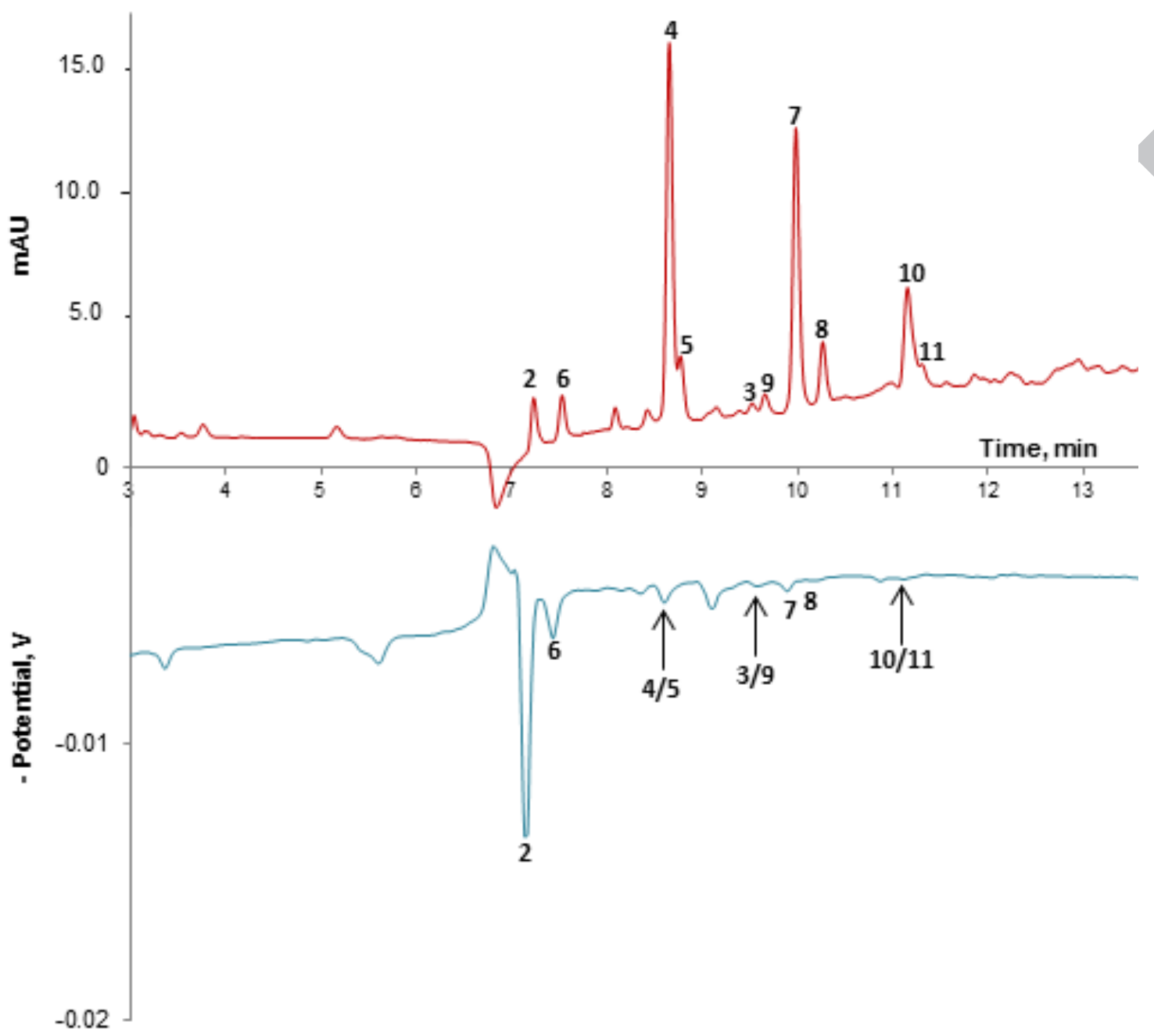


Table 1. Elementary composition, retention time, UV (nm), $[\mathrm{M}-\mathrm{H}]^{-}, \mathrm{MS}^{2}[\mathrm{M}-\mathrm{H}]^{-}$data and ECD responses (nAs) for compound (C) 1 to 13 from EAF

\begin{tabular}{|c|c|c|c|c|c|c|c|}
\hline $\mathrm{C}$ & $\begin{array}{l}\text { Elementary } \\
\text { Composition }\end{array}$ & $\begin{array}{l}\mathrm{RT} \\
(\min )\end{array}$ & UV & {$[\mathrm{M}-\mathrm{H}]-$} & ppm & MS/MS fragmentation pattern & ECD \\
\hline 1 & \multirow{3}{*}{$\mathrm{C}_{18} \mathrm{H}_{14} \mathrm{O}_{9}$} & 3.256 & $\begin{array}{l}205, \\
274 \mathrm{sh}\end{array}$ & 373.0564 & -0.27 & $\begin{array}{l}355.0448\left(-\mathrm{H}_{2} \mathrm{O}\right), 329.0184,311.0554,305.0575,287.0556,269.0460,243.0689,229.0135 \\
\left(-1 \mathrm{PGU},-\mathrm{H}_{2} \mathrm{O}\right), 214.2045,207.0282,181,0493,165.0192,139.0370,125.0244\end{array}$ & - \\
\hline 2 & & 7.048 & $\begin{array}{l}210, \\
272 \mathrm{sh}\end{array}$ & 373.0560 & -1.34 & $\begin{array}{l}355.0459\left(-\mathrm{H}_{2} \mathrm{O}\right), 329.0659,305.0661,287.0558,261.0764,243.0667,231.0286\left(-1 \mathrm{PGU},-\mathrm{H}_{2} \mathrm{O}\right. \\
+2), 216.0062,205.0506,189.0558,165.0191,149.0239,141.0187,124.0157(-1)\end{array}$ & $63.10 \pm 1.54$ \\
\hline 3 & & 9.324 & 213 & 373.0590 & 6.70 & $\begin{array}{l}329.0381,311.0579,259.0246,247.0243 \text { (-1PGU), } 229.0140\left(-1 \mathrm{PGU},-\mathrm{H}_{2} \mathrm{O}\right), 219.0287,201.0190, \\
177.0211,161.0223,141.0191,125.0248\end{array}$ & - \\
\hline 4 & \multirow{2}{*}{$\mathrm{C}_{24} \mathrm{H}_{18} \mathrm{O}_{12}$} & 8.335 & $\begin{array}{l}208, \\
273 \text { sh }\end{array}$ & 497.0729 & 0.80 & $\begin{array}{l}479.0619(-18), 453.0814,435.0720,413.0511,395.0395,371.0411(-1 \mathrm{PGU}), 353.0307 \\
(-1 \mathrm{PGU},-18), 335.0200\left(-1 \mathrm{PGU},-2 \mathrm{H}_{2} \mathrm{O}\right), 325.0353,309.0404,287.0191,267.0305,247.0242(- \\
2 \mathrm{PGU},+2), 229.0145\left(-2 \mathrm{PGU},-\mathrm{H}_{2} \mathrm{O},+2\right), 219.0299,203.0348,191.0346,165.0190,139.0032\end{array}$ & \multirow{2}{*}{$-5.63 \pm 0.59$} \\
\hline 5 & & 8.471 & $\begin{array}{l}210, \\
271 \mathrm{sh}\end{array}$ & 497.0717 & -1.61 & $\begin{array}{l}79.0612\left(-\mathrm{H}_{2} \mathrm{O}\right), 453.0792,435.0693,411.0718,395.0363,371.0404(-1 \mathrm{PGU}), 353.0292(-\mathrm{PGU}, \\
\left.-\mathrm{H}_{2} \mathrm{O}\right), 339.0500,327.0507,309.0390,283.0250,267.0305,247.0242(-2 \mathrm{PGU},+2), 229.0133 \\
\left(-2 \mathrm{PGU},-\mathrm{H}_{2} \mathrm{O},+2\right), 205.0496,165.0199,139.0031,125.0234\end{array}$ & \\
\hline 6 & \multirow{3}{*}{$\mathrm{C}_{30} \mathrm{H}_{22} \mathrm{O}_{15}$} & 7.535 & $\begin{array}{l}211, \\
275 \mathrm{sh}\end{array}$ & 621.0880 & -0.97 & $\begin{array}{l}\left.\text { 603.0769 (- } \mathrm{H}_{2} \mathrm{O}\right), 577.0974,541.0765,477.0423\left(-1 \mathrm{PGU},-\mathrm{H}_{2} \mathrm{O}\right), 455.0613,433.0548,413.0507, \\
373.0526(-2 \mathrm{PGU},+2), 343.0442,311.0205,287.0200,247.0262,207.0291\left(-3 \mathrm{PGUs},-2 \mathrm{H}_{2} \mathrm{O}\right), \\
165.0189,125.0241\end{array}$ & $24.63 \pm 1.54$ \\
\hline 7 & & 9.708 & $\begin{array}{l}208, \\
275 \mathrm{sh}\end{array}$ & 621.0891 & 0.81 & $\begin{array}{l}603.0782\left(-\mathrm{H}_{2} \mathrm{O}\right), 585.0654\left(-2 \mathrm{H}_{2} \mathrm{O}\right), 559.0864,537.0660,479.0607\left(-1 \mathrm{PGU},-\mathrm{H}_{2} \mathrm{O},+2\right), 433.0539, \\
371.0400(-2 \mathrm{PGUs},+2), 353.0301\left(-2 \mathrm{PGUs},-\mathrm{H}_{2} \mathrm{O},+2\right), 335.0194\left(-2 \mathrm{PGUs},-2 \mathrm{H}_{2} \mathrm{O},+2\right), 309.0401, \\
283.0233,249.0403,229.0140,205.0503\left(-3 \mathrm{PGUs},-2 \mathrm{H}_{2} \mathrm{O},-2\right), 163.0404,139.0034\end{array}$ & $2.52 \pm 0.16$ \\
\hline 8 & & 9.964 & $\begin{array}{l}212, \\
273 \text { sh }\end{array}$ & 621.0879 & -1.13 & $\begin{array}{l}603.0778\left(-\mathrm{H}_{2} \mathrm{O}\right), 585.0670\left(-2 \mathrm{H}_{2} \mathrm{O}\right), 559.0875,519.0539,477.0454\left(-1 \mathrm{PGU},-\mathrm{H}_{2} \mathrm{O}\right), 433.0565 \\
\text { 413.0302, 393.0224, } 371.0398(-2 \mathrm{PGUs},+2), 339.0502,309.0391,283.0272,245.0079 \\
(-3 \text { PGUs, }+2), 205.0492\left(-3 \text { PGUs, }-2 \mathrm{H}_{2} \mathrm{O},-2\right), 139.0029\end{array}$ & $1.32 \pm 0.18$ \\
\hline 9 & \multirow{3}{*}{$\mathrm{C}_{36} \mathrm{H}_{26} \mathrm{O}_{18}$} & 9.423 & 212 & 745.1058 & 1.61 & $\begin{array}{l}727.0949\left(-\mathrm{H}_{2} \mathrm{O}\right), 701.1124,659.0818,579.0816,537.0685,477.0475\left(-2 \mathrm{PGU},-\mathrm{H}_{2} \mathrm{O},+2\right), \\
411.0348,355.0414,311.0225\left(-3 \mathrm{PGU},-3 \mathrm{H}_{2} \mathrm{O},-2\right), 249.0416,205.0158\left(-4 \mathrm{PGU},-2 \mathrm{H}_{2} \mathrm{O}\right), 163.007\end{array}$ & - \\
\hline 10 & & 11.009 & $\begin{array}{l}212, \\
272 \mathrm{sh}\end{array}$ & 745.1046 & & $\begin{array}{l}727.0935\left(-\mathrm{H}_{2} \mathrm{O}\right), 665.0639,619.0747(-1 \mathrm{PGU}), 585.0676\left(-1 \mathrm{PGU},-2 \mathrm{H}_{2} \mathrm{O},+2\right), 559.0870,517.0385, \\
477.0472\left(-2 \mathrm{PGU},-\mathrm{H}_{2} \mathrm{O},+2\right), 441.0237,389.0308,353.0292,309.0442,231.0295,205.0120(-1 \mathrm{PGU}, \\
-36), 177.0194,139.0052\end{array}$ & \multirow{2}{*}{$-0.96 \pm 0.04$} \\
\hline 11 & & 11.112 & 212 & 745.1049 & 0.40 & $\begin{array}{l}\left.727.0943\left(-\mathrm{H}_{2} \mathrm{O}\right), 709.0858\left(-2 \mathrm{H}_{2} \mathrm{O}\right), 619.0735 \text { (-1PGU), 583.0538 (-1PGU, }-2 \mathrm{H}_{2} \mathrm{O}\right), 525.5692, \\
477.0478(-2 \mathrm{PGU},-18,+2), 443.0338,371.0425,339.0503,263.0168,229.0121,203.0354(-4 \mathrm{PGU},- \\
\left.2 \mathrm{H}_{2} \mathrm{O},-2\right), 177.7941,139.0033\end{array}$ & \\
\hline 12 & $\mathrm{C}_{42} \mathrm{H}_{30} \mathrm{O}_{21}$ & 11.732 & - & 869.1238 & 3.57 & $\begin{array}{l}851.1094\left(-\mathrm{H}_{2} \mathrm{O}\right), 833.0920\left(-2 \mathrm{H}_{2} \mathrm{O}\right), 727.0922\left(-1 \mathrm{PGU},-\mathrm{H}_{2} \mathrm{O},+2\right), 693.0811,641.0496,601.0574 \\
\left(-2 \mathrm{PGU},-\mathrm{H}_{2} \mathrm{O},+2\right), 567.0528,513.0421,497.0697,477.0392,409.0238,353.0272,337.0401\end{array}$ & - \\
\hline
\end{tabular}




\begin{tabular}{llll}
\hline & & & $229.0136,204.8425\left(-5 \mathrm{PGU},-2 \mathrm{H}_{2} \mathrm{O},+1\right), 139.0014$ \\
\hline & & & $\begin{array}{l}851.1086\left(-\mathrm{H}_{2} \mathrm{O}\right), 775.0068,744.0918(-1 \mathrm{PGU},+1), 689.0585,619.0710(-2 \mathrm{PGU},+2), 583.0460 \\
\left(-2 \mathrm{PGU},-2 \mathrm{H}_{2} \mathrm{O},+2\right), 511.0480,459.0351,426.0419,373.0522,338.0352,303.3885,229.0143, \\
13\end{array}$ \\
\hline
\end{tabular}
-2PGU, $\left.-2 \mathrm{H}_{2} \mathrm{O},+2\right), 511.0480,459.0351,426.0419,373.0522,338.0352,303.3885,229.0143$,

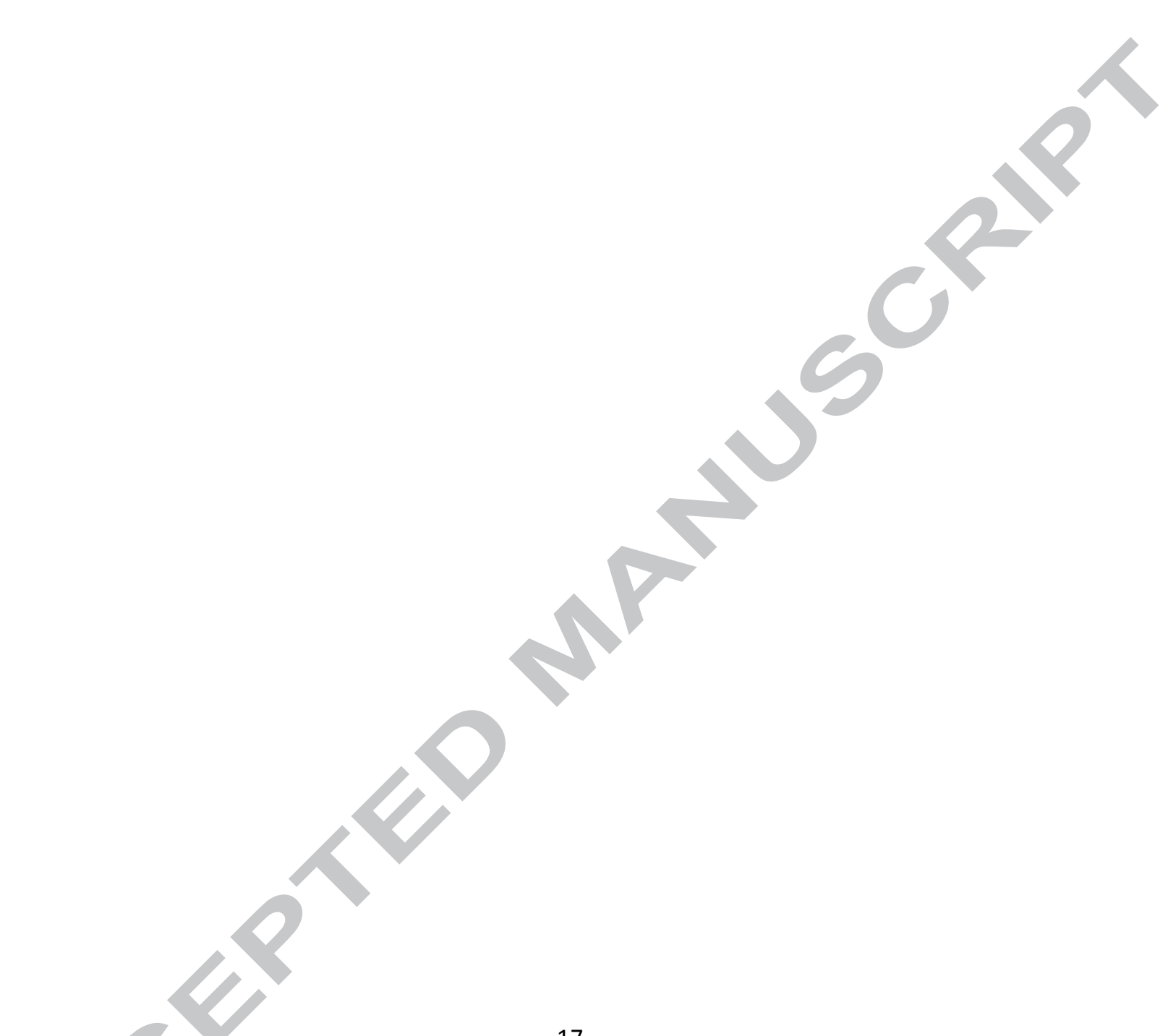

